\title{
Ascorbic Acid, Total Phenolic, Flavonoid and Antioxidant Activity of Two Cultivars of Basella alba
}

\author{
Oduntan Abosede Oluwakemi ${ }^{1, *}$, Akinfasoye Joel Akindele ${ }^{1}$, Fasoyiro Subuola Bosede ${ }^{2}$ \\ ${ }^{1}$ National Horticultural Research Institute Jericho, Nigeria \\ ${ }^{2}$ Institute of Agricultural Research and Training, Nigeria
}

Copyright $(2017$ by authors, all rights reserved. Authors agree that this article remains permanently open access under the terms of the Creative Commons Attribution License 4.0 International License

\begin{abstract}
Antioxidants and secondary metabolites have attracted a great deal of attention for their effect in preventing disease due to oxidative stress. In this study, two cultivars of Basella alba were evaluated for the ascorbic acid, total phenolic, flavonoid and total antioxidant activities by standard methods. Ascorbic acid of green cultivar was $19.38 \mathrm{mg} / 100 \mathrm{~g}$ and red cultivar was $25.85 \mathrm{mg} / 100 \mathrm{~g}$ fresh weight, highly significant difference $(p<0.05)$ was observed in ascorbic acid. Total phenolic contents were 61.00 and $90.52 \mathrm{mg} / \mathrm{g}$ fresh weight for the green and red cultivar respectively, flavonoid content of the green cultivar was $13.37 \mathrm{mg} / \mathrm{g}$ while red cultivar was $17.7 \mathrm{mg} / \mathrm{g}$ significant difference was observed in the ferric reducing power of the two cultivars. DPPH of green cultivar was $78.85 \%$ while for red cultivar was $79.81 \%$, no significant difference was observed between the cultivars. Total antioxidant activity for green cultivar was $60.86 \mathrm{mg} / \mathrm{g}$ while for red cultivar was $70.38 \mathrm{mg} / \mathrm{g}$ fresh weight, no significant difference was observed in the total antioxidant activity. Both cultivars were excellent sources of ascorbic acid, total phenolic compound, flavonoid and total antioxidant properties although red cultivar had higher values.
\end{abstract}

Keywords Antioxidant Supplement, Basella alba, Leafy Vegetable, Nutraceuticals, Underutilize

\section{Introduction}

Basella alba is a vegetable grown especially in the rainfall belt of Southern Nigeria. Propagation is usually by seed. It can be planted through direct seed or by transplanting. It is grown as a short-term crop of $2-4$ months without support or as a long-term crop grown on trellises. Harvesting of a short-term crop begins about 3 weeks after sowing. Harvesting is done weekly by pinching the tips at about $15-25 \mathrm{~cm}$. When the plant is staked, harvesting may be delayed till $5-6$ weeks after sowing. The harvested shoot or leaves are wrapped in branches for fresh sales. For long distance transport, cool environment is required. [1].

Basella alba commonly called Ceylon or Malabar spinach is a tropical perennial vine widely used as leafy vegetable. Basella alba is a leafy vegetables of the family Basellaceae which is consumed for their rich vitamins and mineral nutrients. They are cultivated around residential areas and in backyard gardens for easy access during food preparation. Basella species is an underutilized vegetable commonly grown in the Southern part of Nigeria, usually at the back of bathroom or any water outlet or channel in the house. Various parts of the plant are used for the treatment of diseases as well as for different healing activities of human and animal ailments across the globe especially in India and China [14].

Green leafy vegetables are one of the sources of nutrients for growth in man and animal. Basella as an indigenous vegetable is as of today consumed only in the rural areas where it is grown and is not popular. Nutrition plays a central role in alleviating food insecurity and ill health in developing countries. Studies have shown the potential synergetic effect of indigenous African leafy vegetables as nutraceuticals (micro-nutrient dense and medicinal) (IPGRI, 2006). Studies have also shown that indigenous vegetables apart from their inherent nutritional quality also have healing power [16, 20]. Antioxidants are important in disease prevention in both plants and animals and play a very important role in the body defense system and reactive oxygen species [14]. These naturally occurring compounds present in fruits and vegetables act by scavenging harmful free radicals, which are also implicated in the most common cancers and other degenerative diseases; including poor brain function [7]. The mechanism involved for their antidegenerative and anticancerous activity besides retarding oxidative degradation, lies in the fact that such compounds are responsible for induction of enzymes that detoxify carcinogens and also block the formation of cancer by deactivating at least 30 types agents that may cause cancer [15]. Research has shown that consumption of antioxidant rich foods has health benefits such as reduction of 
occurrence and growth of cancer. This is very important in developing countries like Nigeria where cost of health services is not easily affordable. Optimum utilization of indigenous vegetables will also have significant influence on the income of farmers and traders, especially women, and thereby results in the economic growth of the communities and the nation as a whole [13].

Cultivars of Basella alba have not being analyzed for such important compounds and thus the comparative study of the cultivars are desirable both from academic as well as consumer point of view.

\section{Materials and Methods}

\subsection{Chemicals - All Chemicals and Reagents Used Were of Analytical Grade}

\subsection{Sample Collection and Preparation}

Freshly harvested red and green leafy samples of the cultivars of Basella alba vegetable were obtained from the staff quarters of National Horticultural Research Institute. Samples collected were washed with water to remove impurities and air dried for further analysis. Samples of the two Basella cultivars collected from two different plants each were bulked into three replicates for further laboratory analysis.

\subsection{Determination of Ascorbic Acid}

Ascorbic acid was determined using the method described by Barros [3]. The ethanoic extract was diluted with $10 \mathrm{~mL}$ of $0.5 \%$ oxalic acid and the mixture was shaken for $45 \mathrm{~min}$. on orbital shaker at $200 \mathrm{rpm}$ at room temperature and filtered through Whatman No. 4 filter paper. Precisely $1 \mathrm{~mL}$ of the filtrate was mixed with $9 \mathrm{~mL}$ of $0.1 \mathrm{~mol} \mathrm{~L}-1$ of 2, 6- dichlorophenolindophenol. A reagent blank using ddH2O instead of sample was prepared. The

Absorbance was read within $30 \mathrm{~min}$ at $515 \mathrm{~nm}$ against the prepared blank. The ascorbic acid content was calculated using the calibration curve, prepared from L-ascorbic acid.

\subsection{Determination of Total Phenolic Compound}

Total phenolic content (TPC) of extracts was determined using the Folin-Ciocalteu assay described by Chan [6]. Samples $(0.5 \mathrm{ml})$ were introduced into test tubes followed by $2.5 \mathrm{ml}$ of $10 \%$ Folin Ciocalteu reagent and $2 \mathrm{ml}$ of $7.5 \%$ $\mathrm{Na}_{2} \mathrm{Co}_{3}$. The tubes were allowed to stand for $30 \mathrm{~min}$ before absorbance at $765 \mathrm{~nm}$ was measured. The calibration equation for gallic acid was $\mathrm{y}=\mathrm{Y}=0.0014 \mathrm{x}+0.0166\left(\mathrm{R}^{2}=\right.$ $0.9529)$ where $y$ is the absorbance and $x$ is the concentration of gallic acid in $\mathrm{mg} / \mathrm{L}$

\subsection{Determination of Flavonoid}

The $\mathrm{AlCl}_{3}$ method as described by Jagadish [9] was used for determination of the total flavonoid content of the sample extracts. Aliquots of $1.5 \mathrm{ml}$ of extracts were added to equal volumes of a solution of $2 \% \mathrm{AlCl}_{3}$ ( $2 \mathrm{~g}$ in $100 \mathrm{~mL}$ methanol). The mixture was vigorously shaken, and absorbance at 367 $\mathrm{nm}$ was read after $10 \mathrm{~min}$ of incubation. Quercetin was used as a standard for the calibration curve. The flavonoid compound was calibrated using the linear equation based on the calibration curve. The contents of the flavornoid compound were expressed as $\mathrm{mg}$ Quercetin equivalent/g dry weight.

\subsection{Ferric-reducing Antioxidant Power (FRAP)}

The reducing power of the extract was determined according to the method described by Benzie and Strain [4]. Dilution of extract $(1 \mathrm{ml})$ was added to $2.5 \mathrm{ml}$ phosphate buffer $(0.2 \mathrm{M} ; \mathrm{pH} 6.6)$ and $2.5 \mathrm{ml}$ of potassium ferricyanide $1 \%$ $\mathrm{w} / \mathrm{v})$. The mixture was incubated at $50^{\circ} \mathrm{C}$ for $20 \mathrm{~min}$, Trichoroacetic acid solution $(2.5 \mathrm{ml} ; 10 \% \mathrm{w} / \mathrm{v})$ was added to stop the reaction. The mixture was then separated into aliquots of $2.5 \mathrm{ml}$ and diluted with $2.5 \mathrm{ml}$ of water. To each diluted aliquot, $500 \mathrm{ml}$ of ferric chloride solution $(0.1 \% \mathrm{w} / \mathrm{v})$ was added. After $30 \mathrm{~min}$, absorbance was measured at $700 \mathrm{~nm}$. FRP was expressed as $\mathrm{mg} \mathrm{GAE} / \mathrm{g}$. The calibration equation for gallic acid was $\mathrm{y}=0.0086 \mathrm{x}+0.00256\left(\mathrm{R}^{2}=\right.$ 0.9779).

\subsection{DPPH Radical-scavenging Activity}

The free radical scavenging activity of the extract was determined by the method described by Braca [5]. Dilution of extract $(0.1 \mathrm{ml})$ was added to $3 \mathrm{ml}$ of 2,2-diphenyl-1-picrylhydrazyl $(5.9 \mathrm{mg} / 100 \mathrm{ml}$ methanol). Absorbance was measured at $517 \mathrm{~nm}$ after $30 \mathrm{~min}$. Radical-scavenging ability was calculated using the formula $\left[\left(A_{0}-A_{1}\right) / A_{0}\right] \times 100$ where $A_{0}$ is the absorbance of the control, and $\mathrm{A}_{1}$ is the absorbance of the extract.

The free radical scavenging activity of the extract was determined by the method described by Braca [5].

\subsection{Determination of Total Antioxidant Activity}

Total antioxidant activity of extract was evaluated by the formation of phosphomolybdenum complex as described by Prieto [16]. About $0.1 \mathrm{ml}$ ethanoic solution of extract $(100 \mathrm{ug} / \mathrm{ml})$ was added to $1.9 \mathrm{ml}$ of reagent solution $(0.6 \mathrm{M}$ $\mathrm{H}_{2} \mathrm{SO}_{4} \quad 28 \mathrm{Mm}$ sodium phosphate and $4 \mathrm{Mm}$ ammonium molybdate). The blank solution contained only $2 \mathrm{ml}$ of reagent solution. The absorbance was measured at $695 \mathrm{~nm}$ after $90 \mathrm{~min}$.

\subsection{Statistical Analysis}

Data were subjected to Statistical analysis using SAS Package. Analysis of variance (ANOVA) was used to separate the means. Fisher test was used in determining the least significant difference (LSD) of the mean. Test of 
significant was done at $5 \%$ probability level.

\section{Result and Discussion}

From the current investigation, ascorbic acid was 19.38 $\mathrm{mg} / \mathrm{g}$ fresh weight for the green cultivar and $25.85 \mathrm{mg} / \mathrm{g}$ fresh weight for the red cultivar. Significant variation $(\mathrm{p}<$ 0.05 ) was observed in ascorbic acid as shown in figure 1. Both cultivars were rich in ascorbic acid, red cultivar was higher in ascorbic acid than the green cultivar. Ascorbic acid is an effective antioxidant which helps to protect the body against cancer and other degenerative diseases such as arthritis and type II diabetes mellitus. It also helps in improving the palatability of the vegetable.

Total Phenolic content of the cultivars were $90.52 \mathrm{mg} / \mathrm{g}$ fresh weight (red) and $61.00 \mathrm{mg} / \mathrm{g}$ fresh weight (green) as seen in figure 2. Red cultivar was higher in total phenol but no significant variation $(\mathrm{p}<0.05)$ was observed. The values showed that both cultivars could serve as good sources of inhibiting effects of mutagenesis and carcinogenesis in humans when incorporated into diet. The antioxidant activity of phenolic compounds is mainly due to their redox properties, which can play an important role in adsorbing and neutralizing free radicals, quenching singlet and triplet oxygen, or decomposing peroxides [13].

Flavonoid of red cultivar was $17.70 \mathrm{mg} / \mathrm{g}$ fresh weight while green cultivar was $13.37 \mathrm{mg} / \mathrm{g}$ fresh weight as shown in fig. 3. Among the phenolic compounds are flavonoids which possess biological such as anti-inflammatory, anti-carcinogenic and antiatherosclerotic activities. Flavonoids as one of the most diverse and widespread group of natural compounds are likely to be the most important natural phenolics [2].

Ferric reducing power for the green cultivar was 5.93 $\mathrm{mg} / \mathrm{g}$ while for red cultivar was $10.56 \mathrm{mg} / \mathrm{g}$. As shown in fig.4, reducing power of red cultivar was higher than that of the green cultivar. A significant difference $(p<0.05)$ in ferric reducing power was observed in the cultivars. Antioxidant effect exponentially increases as a function of the development of the reducing power, indicating that the antioxidant properties are concomitant with the development of reducing power [19].

$B$ alba cultivars exhibited a good DPPH radical scavenging activity. The red cultivar had the higher value of $79.81 \%$ while that of green cultivar was $78.85 \%$ (fig. 5 ), no significant difference was observed between the cultivars. The values of scavenging activities are the same to the ones reported by Shyamala [3] which was above 70\%. FRAC and DDPH methods were selected because they measure the capacity of polyphenols in B. alba extract, the differences in the assay is FRAC measures the ability of $\mathrm{B}$. alba to reduce $\mathrm{Fe}^{3+}$ complex of tripyridyltriazine $\mathrm{Fe}(\mathrm{TPTZ})^{3+}$ to the intensely blue coloured $\mathrm{Fe}^{2+}$ complex (Fe(TPTZ) in acidic medium while DPPH measures the ability of B. alba extract to donate hydrogen or electron to the radicals [10].
Total antioxidant activity for the green cultivar was 60.86 $\mathrm{mg} / \mathrm{g}$ fresh weight while for the red cultivar was $70.38 \mathrm{mg} / \mathrm{g}$ fresh weight (figure 6), no significant difference was observed in the total antioxidant activity. In comparing the antioxidant content and activity of basella species with $U$. cylindrica of $74.65 \mu \mathrm{g} \mathrm{AA} / \mathrm{g}$ is high in antioxidant as reported by Manojlovic [11]. This result suggested that basella species could be considered as natural antioxidants in food processing.

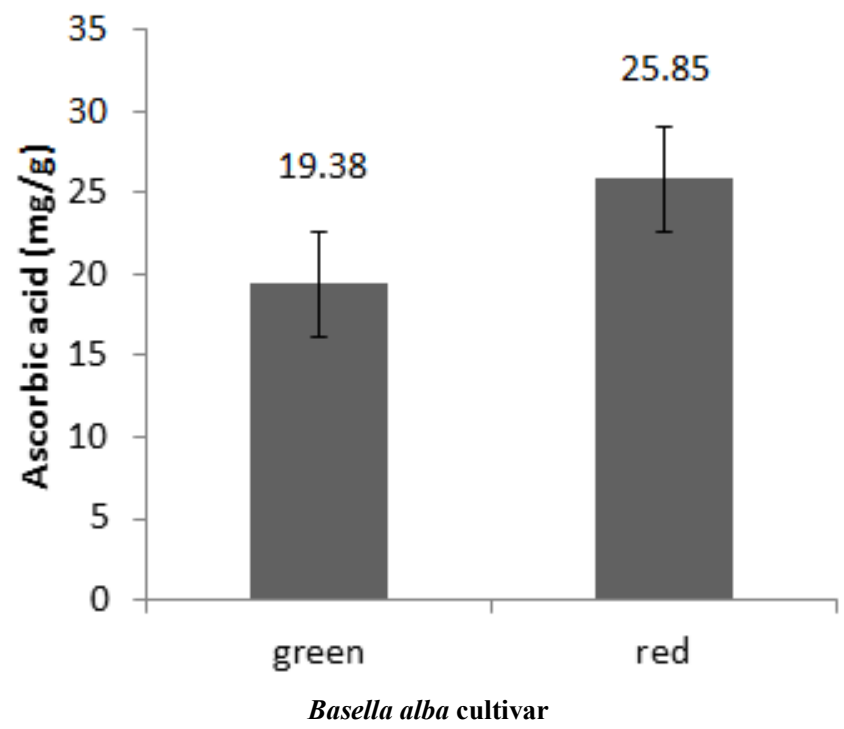

Figure 1. Ascorbic acid contents of the two cultivars of Basella

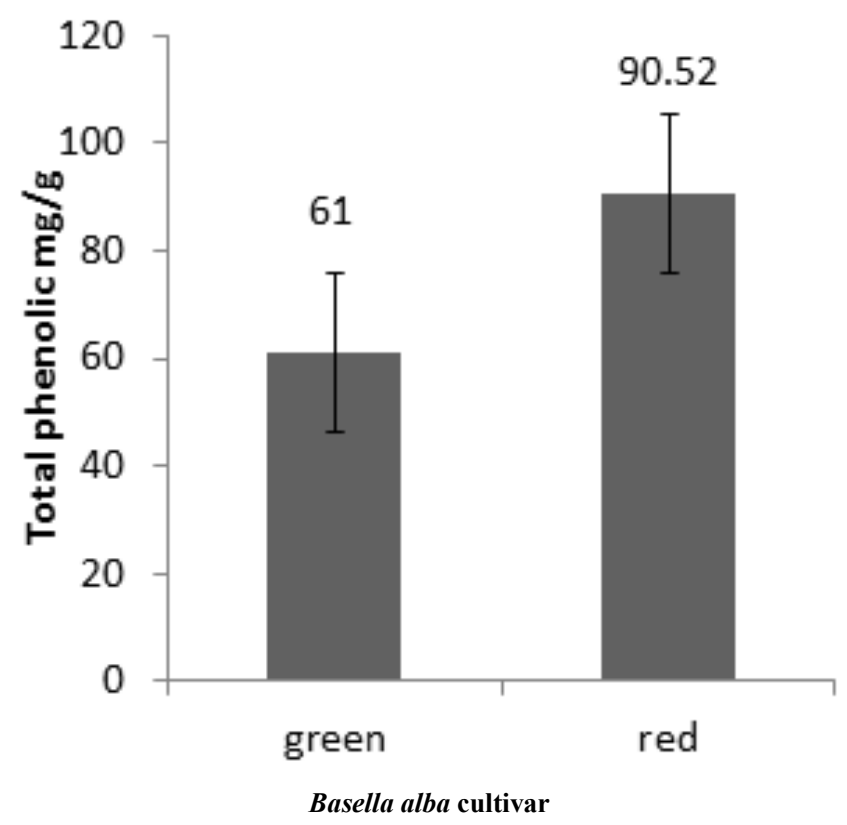

Figure 2. Total phenolic content of the two cultivars 


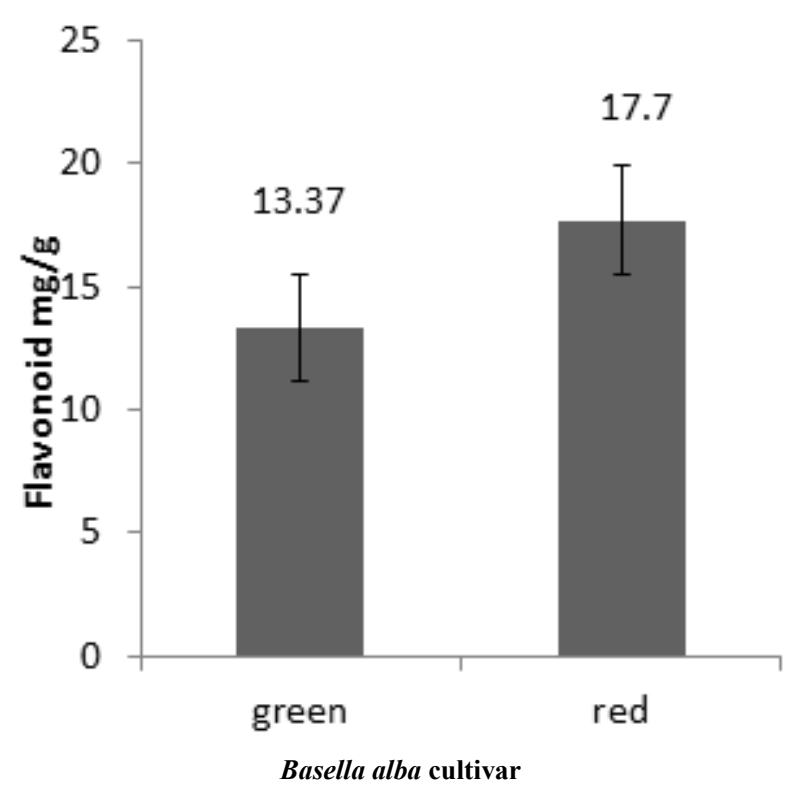

Figure 3. Flavonoid content of the two cultivars

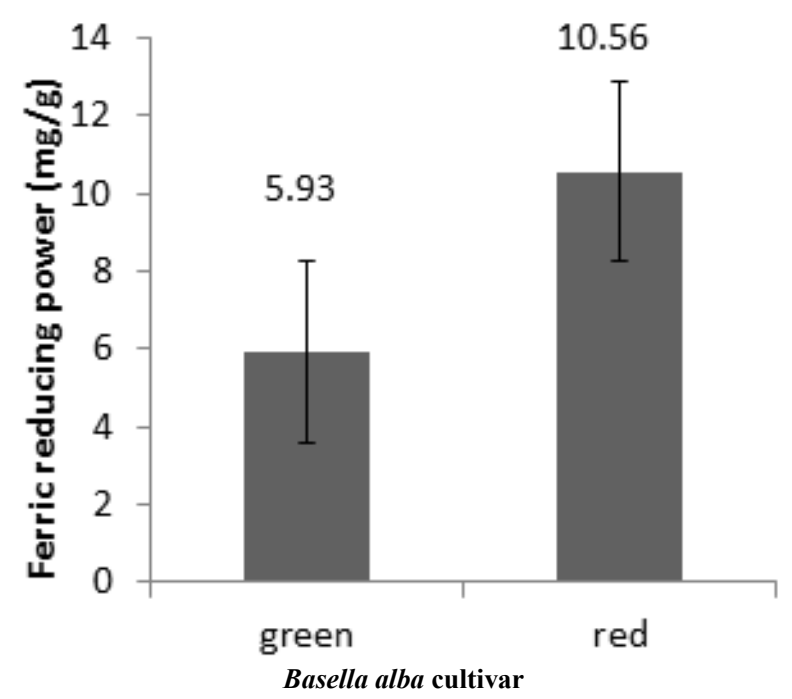

Figure 4. Ferric reducing power of the two cultivars

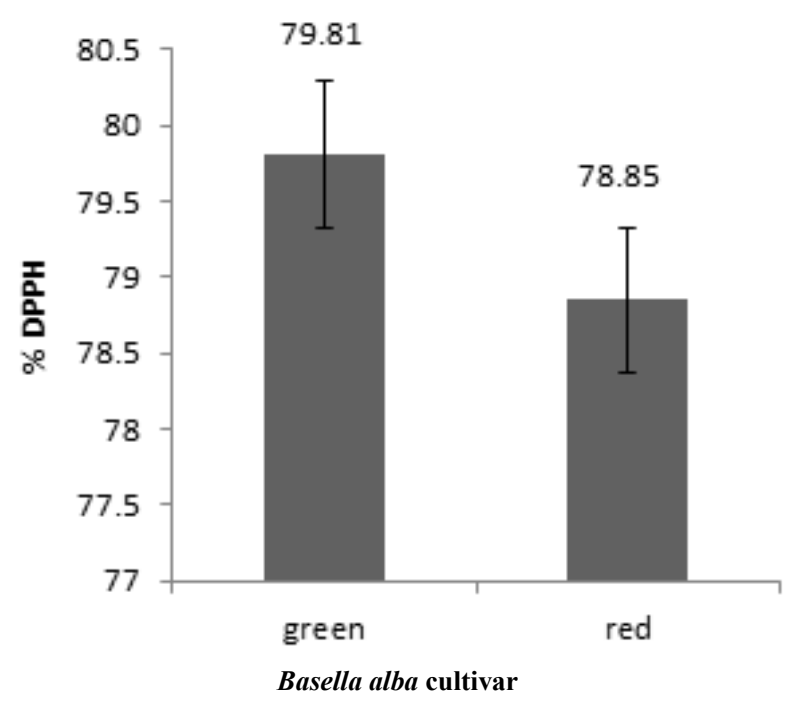

Figure 5. Percent DPPH of the two cultivars

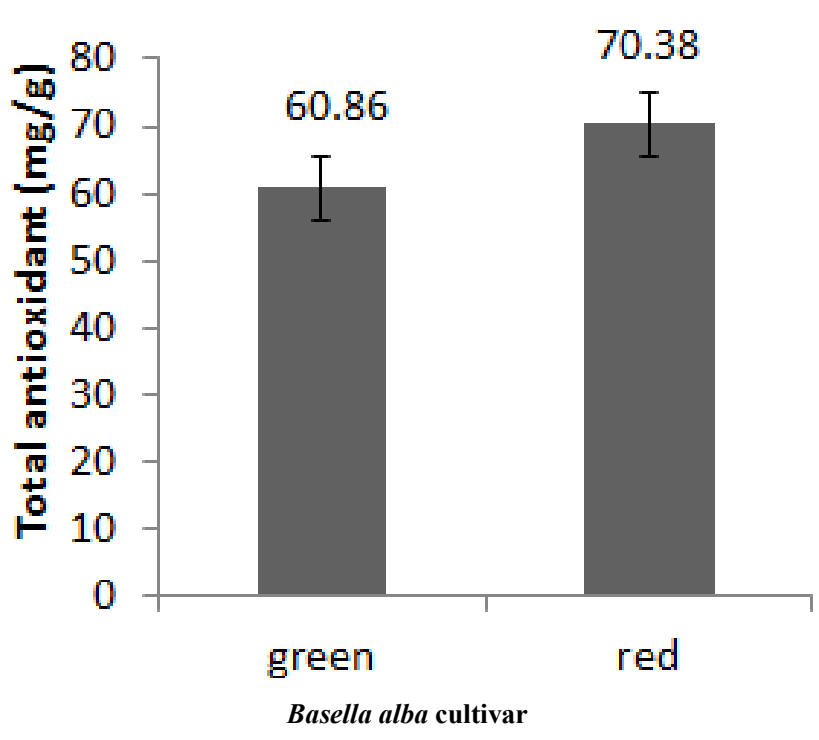

Figure 6. Total antioxidant activity of the two cultivars

\section{Conclusions}

Green and red cultivars of Basella alba are very good sources of ascorbic acid, phenolic compounds and have a high antioxidant activity. Thus both cultivars could serve as natural antioxidant supplement as alternative to synthetic supplements. This leafy vegetable possesses higher potential which may be used against oxidative stress and thus act as strong anticancerous as well as antidegenerative foods. Therefore, there is the need to improve the cultivation and utilization of the vegetable.

\section{REFERENCES}

[1] M.O. Abukutsa-Onyago, Basella alba L. In: (Grubben, G.J.H. and Denton, O.A. Editors). Plant Resources of Tropical Africa, Vegetables, Prota Foundation, Wageningen, Netherlands/CTA Wageningen, Netherlands. Pp 103 - 106, 2004.

[2] P.K. Agrawal, Carbon-13 NMR of flavonoids. New York: Elsevier, (1989).

[3] L. Barros; M. Joao Ferreira; B. Queiros; I.C. Ferreira; P. Baptista, Total phenol, ascorbic acid, $\beta$ - carotene and lycopene in Portuguese wild edible mushroom and their antioxidant activities. Food Chemistry, 413-419, 2007.

[4] I.F.T. Benzie and J.J, Strain Ferric reducing antioxidative power assay. Methods Enzymol, 299: 15-27, 1999.

[5] A. Braca; N.D. Tommasi; L.D. Bari; C. Pizz; M. Politi; I Morelli, Antioxidant principles from Bauhinia terapotensis, Journal of Natural Products, 64: 892-895, 2001.

[6] E.W.C. Chan; Y.Y. Lim, S.K. Wong; K.K. Lim; F.S. Lianto, Antioxidant and tyrosinase inhibition properties of leaves and rhizomes of ginger species. Food Chemistry, 109: 477-483, 2008. 
[7] C.J. Dillard, J.B. German, Phytochemicals: nutraceuticals and human health. Journal Science Food Agriculture, 80: 1744-1756, 2000.

[8] IPGRI., Reducing hidden hunger and malnutrition through traditional foods. IPGRI newsletter for Sub-Saharan Africa. Nairobi, Kenya. 2006; 1-3.

[9] L.K. Jagadish; V.V. Krishnan; R. Shenbhagaraman; V. Kaviyarasan, Comparative study on the antioxidant, anticancer and antimicrobial property of Agaricus bisporus imbach before and after boiling. Africa Journal of Biotechnology, 8: 654-661. 2009.

[10] Y.Y. Lim, T.T Lim, J.J Tee. Antioxidant properties of guava fruit: comparison with some local fruits. Sunway Acad. J. 3: 9-20, 2006.

[11] N.T. Manojlovic, P. J. Vasiljevic, P. Z. Maskovic, M. Juskovic, and G. Bogdanovic-Dusanovic. Chemical Composition, Antioxidant, and Antimicrobial Activities of Lichen Umbilicaria cylindrica (L.) Delise (Umbilicariaceae), Evidence-Based Complementary and Alternative Medicine Volume 2012, 8 pages.

[12] A.O. Oduntan; B.A. Akinwande and O. Olaleye, Effect of plant maturity on the antioxidant properties, total phenolic and mineral contents of Sesamum radiatum leaves. African Journal of food Science, 5 (17): 914 - 920, 2011.

[13] T. Osawa, Novel naural antioxidants for utilization in food and biological systems. In I. Uritani, V. V. Garcia and E. M. Mendoza (Eds) Postharvest biochemistry of plant food materials in the tropics. (Tokyo, Japan: Japan scientific societies press) pp. 241-251, 1994.

[14] H. Ou; Hampsch; J.A. Flanagan, \& K.D. Elizabeth, K.D. Analysis of antioxidant activities of common vegetables employing oxygen radical absorbance capacity (ORAC) and ferric reducing antioxidant power (FRAP) assays:A comparative study: Journal of Agricultural Food Chemistry, 50 (11): 3122-3128, 2002.

[15] M. Percival, Nutritional support for connective tissue repairs and wound healing. Clinical Nutrition Insights, 5: $1-5$. 1997

[16] B.M. Popkin; S. Horton and Kim, The nutrition transition and prevention of diet-related diseases in Asia and the Pacific, Food Nutrition Bulletin. 22: Supplement 58. 2001.

[17] P.Prieto, M. Pineda, M. Aguilar. Spectrophotometric quantitation of antioxidant capacity through the formation of a phosphomol ybdenum complex. Specific application to the determination of Vit E. Anal. Biochem, 269: 337 - 341, 1999.

[18] A. Roshan, K.H.N. Naveen, S.D. Shruthi. A Review on Medicinal Importance of Basella alba L. International Journal of Pharmaceutical Sciences and Drug Research. 4 (229): $110-114,2012$.

[19] M. Tanaka, C.W. Kure, Y. Nagashima, and T. Taguchi. Applications of ant oxidative Maillard reaction products from histidine and glucose to sardine products. Nippon Suisan Gakkaishi, 54: 1409-1414, 1988.

[20] R.R. Schippers. African indigenous vegetables. An overview of the cultivated species. Chatham, UK. Natural Resources Institute/ACP-EU Technical Centre for Agricultural and Rural Cooperation, 2002.

[21] B.N. Shyamala, G. Sheetal, J.A. Lakshmi, J. Prakash. Leafy vegetable extracts- antioxidant activity and effect on storage stability of heated oils. Innovative Food Science Emerging Technology, 6: 239-245, 2005. 